\title{
Long-term monitoring and field testing of an innovative multistory timber building
}

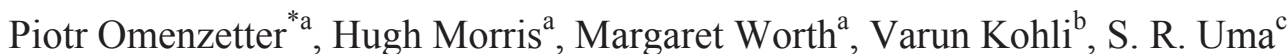 \\ ${ }^{a}$ The University of Auckland, Private Bag 92019, Auckland, New Zealand; \\ ${ }^{\mathrm{b}}$ The University of California, Berkeley, CA 94720-1710, USA; \\ ${ }^{\mathrm{c}}$ GNS Science, Lower Hutt 5040, New Zealand
}

\begin{abstract}
An innovative three-story timber building, using self-centering, post-tensioned timber shear walls as the main horizontal load resisting system and lightweight composite timber-concrete floors, has recently been completed in Nelson, New Zealand. It is expected to be the trailblazer for similar but taller structures to be more widely adopted. Performance based standards require an advanced understanding of building responses and in order to meet the need for in-situ performance data the building has been subjected to forced vibration testing and instrumented for continuous monitoring using a total of about 90 data channels to capture its dynamic and long-term responses. The first part of the paper presents a brief discussion of the existing research on the seismic performance of timber frame buildings and footfall induced floor vibrations. An outline of the building structural system, focusing on the novel design solutions, is then discussed. This is followed by the description of the monitoring system. The paper emphasizes the need for optimal placement of a limited number of sensors and demonstrates how this was achieved for monitoring floor vibrations with the help of the effective independence-driving point residue (EfI-DPR) technique. A novel approach to the EfI-DPR method proposed here uses a combinatorial search algorithm that increases the chances of obtaining the globally optimal solution. Finally, the results from the forced vibration tests conducted on the whole building at different construction stages are reviewed.
\end{abstract}

Keywords: Timber structures, structural health monitoring, dynamic testing, optimal sensor location, system identification

\section{INTRODUCTION}

Modern multistory timber buildings, six to nine stories high, have been constructed in countries including Germany, England, Canada and Sweden. An example of this trend is the construction of an innovative three-story office structure, using self-centering, post-tensioned timber shear walls as the main horizontal load resisting system and lightweight composite timber-concrete floors, recently completed in New Zealand for the Nelson Marlborough Institute of Technology (NMIT). The preliminary design concept won a funding contribution from the New Zealand Ministry of Agriculture and Forestry (MAF) in competition for a timber government building of a commercial scale. The project is expected to be the trailblazer for similar, possibly taller, structures to be more widely adopted locally.

Performance based design requires the understanding of structural responses to the various loads acting on structures. Insitu, full-scale structural monitoring and testing can provide invaluable insights and help avoid the many simplifications and assumptions present in analytical or numerical simulations and laboratory experimentation. Modest MAF funding was obtained to install permanent instrumentation into the building investigating several aspects of structural performance relevant for timber structures in a strong seismic and wind environment. One-off, ambient and forced dynamic tests were also conducted.

The outline of this paper is as follows. Firstly, a brief literature survey is included that highlights previous research attempts aiming at a better understanding of the issues in dynamic performance of timber frame buildings. Issues in footfall induced vibrations of lightweight floors and their monitoring are also covered. Then, the NMIT building and its structural systems are described with the focus on the seismic and wind load bearing shear walls and composite timberconcrete floors. The comprehensive monitoring system designed for the building and comprising sensors to measure both

p.omenzetter@auckland.ac.nz; phone 649 923-8138; fax 649 373-7462; www.auckland.ac.nz 
long-term and slowly varying timber deformations due to creep and temperature and humidity variations, as well as dynamic responses produced by wind, ground shaking and, in case of floors, footfall is discussed. One of the challenges of monitoring the vibrations of irregular floors was placing a limited number of sensors in an optimal manner and the paper reports on how this was approached. Finally, the results of several one-off ambient and forced dynamic testing exercises conducted at various construction stages are reviewed.

\section{LITERATURE REVIEW}

This section is a brief literature review that surveys existing research into the dynamic performance of timber frame buildings and footfall induced vibrations of lightweight floors - two topical areas that the dynamic monitoring system of the NMIT building is targeting for real-life data.

\subsection{Dynamic performance of timber frame buildings}

Strong earthquakes, such as the 1994 Northridge earthquake and the 1995 Kobe earthquake exposed the vulnerabilities of timber frame structures. These were attributed to the lack of adequate performance based design procedures for timber ${ }^{1}$. Such procedures need to draw on full-scale experimental data, however, few full-scale seismic tests have been conducted to date on multistory light-frame timber buildings and even less on medium to heavy-frame buildings ${ }^{2}$. Some representative tests and their conclusions are reviewed below with emphasis on the influence of non-structural elements on seismic response and amplitude dependence of natural frequencies and damping.

Filiatrault et al. ${ }^{3}$ performed uni-axial shake table tests on a near full-scale two-story light-frame timber building. The building was tested as the bare frame and then with interior and exterior finishings. The fundamental frequency of the building was found to be dependent strongly, a decrease by $40 \%$, on the presence of non-structural elements. Viscous damping for the structure with finishing materials was found to be $7 \%$. The simple structure including finishing materials displayed a near linear response.

Camelo ${ }^{4}$ conducted a series of ambient and forced vibration tests on existing multistory light-frame timber houses with different configurations and heights. Fundamental frequencies found from ambient vibrations were shown to be higher than those obtained from the forced vibration tests; this was attributed to amplitude dependence of modal frequencies. An analysis of the data from the shake table tests performed by Filiatrault et al. ${ }^{3}$ showed a large discrepancy in the damping estimates, with $15 \%-20 \%$ critical damping compared to Filiatrault et al. ${ }^{3}$

Mosalam and Mahin ${ }^{2}$ conducted seismic testing on a typical, near full-scale, asymmetrical, three-story light-frame residential timber building with discontinuities in elevation. The building was tested using a multi-directional shake table without finishes, with finishes, and after retrofitting. The testing confirmed the tendency for the building to twist about the vertical axis and form a weak story mechanism in the lower floor where the tuck-under parking was located. The magnitudes of these tendencies were significantly reduced with retrofit and finishing materials.

Sutoyo ${ }^{5}$ extended on the work done by Camelo ${ }^{4}$ by investigating the performance of light-frame timber buildings at high shaking levels. The study used earthquake records from two instrumented light-frame timber buildings. Experimental shake table records from a two and three-story timber frame house were also used. The results showed amplitude dependence for both fundamental frequency and damping estimates. The fundamental frequencies dropped at higher amplitudes and the damping ratios increased for stronger motion. Hysteretic loops were extracted from the earthquake records and from the shake table records. This worked well for the shake table data, however, less so for the earthquake data. Modal parameters of the shake table records were compared to the hysteretic loops and their validity discussed. When a linearized model is used to estimate modal parameters of a timber building experiencing large seismic motions, damping ratios of $12-20 \%$ can be expected. For a timber building displaying linear behavior damping ratios of 5-10\% can be expected. A non-linear model with a custom hysteretic model would use a viscous damping estimate of 5-10\%. This explains the discrepancies seen in damping estimates in Camelo ${ }^{4}$ and Filiatrault et al. ${ }^{3}$

A representative finite element model was constructed with the help of various model updating techniques. The model was used as a validation tool to assess the accuracy of extracting the building's hysteretic loops from earthquake records. The hysteretic loops extracted from the updated finite element model were shown to be more consistent with current knowledge of timber frame structures than those extracted from the earthquake records. It was concluded that a substantial amount of information about the hysteretic behavior of timber frame buildings could be extracted from earthquake records such as hysteretic curves, structural deformations and amount of energy dissipated. The seismic 
record database would however substantially benefit from multi-axial sensors placed strategically. The integration of model updating into the investigations was seen as highly useful.

Filiatrault et al. ${ }^{6}$ tested a full-scale, two-story, light-frame town house building on two tri-axial shake tables operating in unison. The influence of internal gypsum wallboards and external stucco was investigated. These were shown to improve the seismic response substantially, reducing the first floor drift by $66 \%$. Looking at hysteretic response of the centre of the roof indicated that the wall finishes not only reduced its displacement, but also changed its overall hysteretic characteristics. The timber-only building showed a moderate non-linear response, whereas the other configurations showed an almost linear response. It was concluded that the development of a performance based seismic design method taking into account the effect of wall finishing materials was urgently needed. The building also displayed a weak story mechanism and significant torsional response due the garage opening on the first floor.

Van de Lindt et al. ${ }^{7}$ tested a full-scale, light-frame, seven story timber building on the Japan's E-Defense largest shake table. The objective of the test was to assess the seismic performance of mid-rise light frame timber building with a steel moment resisting frame in the first story. The testing showed that the mid-rise light frame timber buildings performed better than what was expected from current guidelines and codes.

Ellis and Bougard ${ }^{8}$ dynamically tested a six-story medium-frame timber building at different stages during construction. The purpose of this was to quantify the difference between the stiffness of the bare timber frame of the building, which was used in the dynamic design, and the stiffness of the complete building. Ambient and forced vibration tests were used to measure the characteristics of all the fundamental modes at three key stages of construction: the bare timber frame, the timber frame with staircase, plasterboard walls and ceiling lining, and when the building was completed including the masonry cladding. Results from the experiments showed that the stiffness was increased five-fold for torsion due to the addition of the masonry cladding. The plasterboard and the stairway also had a large effect on the translational stiffness of the building. Results also showed that with increasing seismic amplitudes, the modal frequencies decreased and the damping ratios increased. The authors concluded that an important method for the understanding of the building behavior is using numerical modeling combined with experimental measurements at various stages of construction.

Filiatrault and Foltz ${ }^{9}$ discussed how timber frame buildings are generally designed as individual components without due consideration for their mutual interaction; unlike the design of steel and concrete buildings, for which capacity design principles have been developed. They reasoned that timber frame building design would therefore benefit greatly from a rational performance based seismic design procedure. The procedure developed used the direct displacement design method as a basis. The procedure did take into account damping due to non-structural components, however, it did not take into account any additional stiffness due to non-structural components.

Filiatrault et al. ${ }^{1}$ proposed a simple equation for the variation of global viscous damping against building drift to facilitate the use of direct displacement design. To do this, a finite element model was developed to model the global load-displacement behavior and the variation of the global equivalent damping with displacement amplitude. The model was then validated against the results from shake table testing. It was found that the global equivalent damping ratio against building drift displayed consistent behavior. For building drifts less that $0.4 \%$, it was found that the damping ratio increased linearly to around $18 \%$ of critical damping. For building drifts more than $0.4 \%$, the damping ratio stayed relatively constant around $18 \%$. This, however, did not take into account damping from non-structural elements or structural elements other that the parameter shear walls, and to account for this an additional damping ratio of $2 \%$ was added.

Pang and Rosowsky ${ }^{10}$ built on the procedure proposed by Filiatrault and Foltz ${ }^{9}$ by considering a multi degree of freedom model. Interstory drift limits were determined for three different performance levels: immediate occupancy, life safety and collapse prevention. The procedure, however, is only applicable to timber frame buildings with a relatively symmetric plan and regular shape. An advantage of the procedure is that it avoids the necessity of a non-linear push over analysis as an equivalent viscous damping ratio is not necessary for calculations; however, it does require information about shear wall backbone curves.

In conclusion, experimental investigations on the seismic performance of light timber frame buildings show conclusive results on the amplitude dependence of both damping and fundamental frequency, significant effect of non-structural elements on stiffness, the tendency for a weak story mechanism to form, and the effect of asymmetry on torsional modes. Design procedures have been developed for light-frame timber buildings, however, they do not take into account the effect of wall finishings on global stiffness and hysteretic performance. Further studies need also to be done on the effect of non-structural elements on the hysteretic performance of buildings. Less research has been performed on medium to 
heavy timber frame buildings, however, there are some similar seismic characteristic to light-frame timber buildings, such as amplitude dependence of both damping and fundamental frequency and increasing global stiffness due to nonstructural elements. The usefulness of combining numerical modeling with experimental measurements at various stages of construction to deepen the understanding of seismic performance has also been established but needs to be more vigorously pursued.

\subsection{Footfall induced floor vibrations and their monitoring}

Improved mechanical properties of construction materials have enabled engineers to design lighter and more slender structures. In addition to economic factors, this is often driven by the desire to achieve more aesthetically pleasing architectural expression. The current push towards stronger and lighter materials and structural systems is resulting in increasing liveliness of long-span floors in buildings. Modern floors with large spans are lightweight constructions with low stiffness and low natural frequencies, and are therefore more easily excited by dynamic footfall loading. With an increasing number of floors failing in their vibration serviceability ${ }^{11}$, robust methods for the assessment of floor vibration have become essential. Footfall induced footfall loading has proved to be the major source of floor vibration disturbance. Excessive floor vibrations due to walking and similar activities can be considered as probably the most persistent floor serviceability problem encountered by designers.

The difficulty in vibration design is the poor correlation between the outcome of computations at the design stage and the response of the floor constructed accordingly. In addition to the uncertainties inherent in material properties, damping characteristics and boundary conditions, the level of vibrations perceived by individuals, the vibration that is considered objectionable, and the force and frequency of foot drop are all highly subjective and/or prone to large variations ${ }^{12}$.

During walking, a pedestrian produces a dynamic time varying force which has components in all three directions: vertical, horizontal-lateral and horizontal-longitudinal. The vertical component of the force is relevant for floor vibrations and has been experimentally quantified. Andriacchi et al. ${ }^{13}$ measured single step walking forces in all three directions by means of a force plate. Hechler et al. ${ }^{14}$ measured the step frequency of 200 persons passing the entrance hall of an administration building. It was noted that all footfall loading parameters are highly different for different persons but some general conclusions can be drawn.

A reliable statistical description of normal walking frequencies was given by Matsumoto et al. ${ }^{15,16}$, who investigated a sample of 505 persons. They concluded that the frequencies followed a normal distribution with a mean pacing rate of $2.0 \mathrm{~Hz}$ and standard deviation of $0.173 \mathrm{~Hz}$. Leonard ${ }^{17}$ concluded that the normal walking frequency range is $1.7-2.3 \mathrm{~Hz}$, which is in broad agreement with the findings of Matsumoto et al. There are also some proposals as to the typical frequency ranges for different human activities (running, jumping, bouncing, etc.), e.g., Bachmann et al. ${ }^{18}$ defined typical frequency ranges of 1.6-2.4 Hz for walking, 2.0-3.5 Hz for running, 1.8-3.4 Hz for jumping, 1.5-3.0 Hz for bouncing and $0.4-0.7 \mathrm{~Hz}$ for horizontal body swaying while stationary.

For an open plan office, an upper limit of $2.1 \mathrm{~Hz}$ for walking pace is acceptable. For low height partitioned office spaces and labs, $1.8 \mathrm{~Hz}$ is more appropriate. In the absence of more detailed information, a walking frequency of $2 \mathrm{~Hz}$ is recommended. Being periodic but non-sinusoidal, walking forcing functions have significant higher harmonics in addition to the fundamental one. Frequencies of these are integer multiplies of the fundamental walking frequency (1.5$2.5 \mathrm{~Hz}$ ) and have the potential to excite the fundamental or other vibration resonances ${ }^{12}$. In design and analysis, the inclusion of several loading harmonics and higher structural modes is often necessary.

While floor dynamic testing has relatively rich literature, comprehensive in-service floor vibration studies through longterm monitoring are comparatively less frequently undertaken, indicating the need for more such research. Samarajiva and Choudhur ${ }^{19}$ monitored structural vibrations in a fitness center area and adjacent computer server room. Aerobic activities were simulated by people spot jogging on the floor. Vibration levels were monitored inside the computer server room, the proposed aerobics area and at a location close to the proposed treadmill area. The vibration levels due to simulated aerobic activities in the computer server room were significantly above the acceptable threshold for the computer equipment room. It was recommended that the floor system be modified to reduce floor vibrations.

Salyards et al. ${ }^{20}$ investigated complaints of disturbing vibration levels from the occupants of a newly constructed academic building. A remote monitoring system was used for floor vibration monitoring. Analysis of the collected data revealed the vibrations were not due to walking but were attributed to several other sources ranging from wind to traffic to mechanical equipment to leg jiggling.

7983 - 108 V. 2 (p.4 of 14) / Color: No / Format: A4 / Date: 2011-01-26 01:37:14 AM 
Huston et al. ${ }^{21}$ describe monitoring of floor vibrations in a steel frame research building housing delicate precision instruments that can be adversely affected by even small floor vibrations. The measurements were compared with industry standards and with measurements taken at nearby reinforced concrete buildings. The efforts at reducing the vibrations due to the mechanical systems of the building were also assessed.

\section{THE NELSON MARLBOROUGH INSTITUTE OF TECHNOLOGY TIMBER BUILDING AND ITS INSTRUMENTATION}

\subsection{Structural system}

The three-story NMIT timber building was completed in January 2011. The NMIT building complex has three seismically separate sections: the one-story Media building, one-story Workshop building and three-story Arts building as shown in Fig. 1. The major building of interest is the Arts building (Fig. 2), which is a combination of staff offices and small classrooms. Structurally, the building has non-moment resisting frames for vertical loads. The key innovation is the provision of dual timber post-tensioned shear walls in both directions. The structural design was based on EXPAN technology developed by the University of Canterbury as part of Structural Timber Innovation Company consortium ${ }^{22}$. The laminated veneer lumber (LVL) shear walls are designed to rock from side to side in a major earthquake and have energy dissipating devices between the two panels of each shear wall pair. The lateral deformation is expected to be up to a maximum of $130 \mathrm{~mm}$ and the shear walls will uplift as much as $50 \mathrm{~mm}$. The post-tensioning is provided by four 32 $\mathrm{mm}$ rods tensioned to $340 \mathrm{kN}$ each. There is specialized detailing to allow the freedom of movement and this includes the major lateral load transfer via cylindrical connectors with Teflon spacers and slotted location bolts so that rotation does not induce moment, and U-shaped yielding steel energy dissipaters (Fig. 3). The shear walls link to the frame and lateral load is transferred through the floor diaphragm.

The majority of the floors use a proprietary LVL floor system with concrete topping, while cantilevered parts are reinforced concrete. The main floor beams are double units $750 \mathrm{~mm}$ x $89 \mathrm{~mm}$ with a sawn pre-camber and shear connectors to provide composite action with the concrete topping. The concrete topping was cast independently over the secondary cross-beams using a membrane to minimize composite action and shrinkage was allowed to occur before the main beams infill toppings were poured.

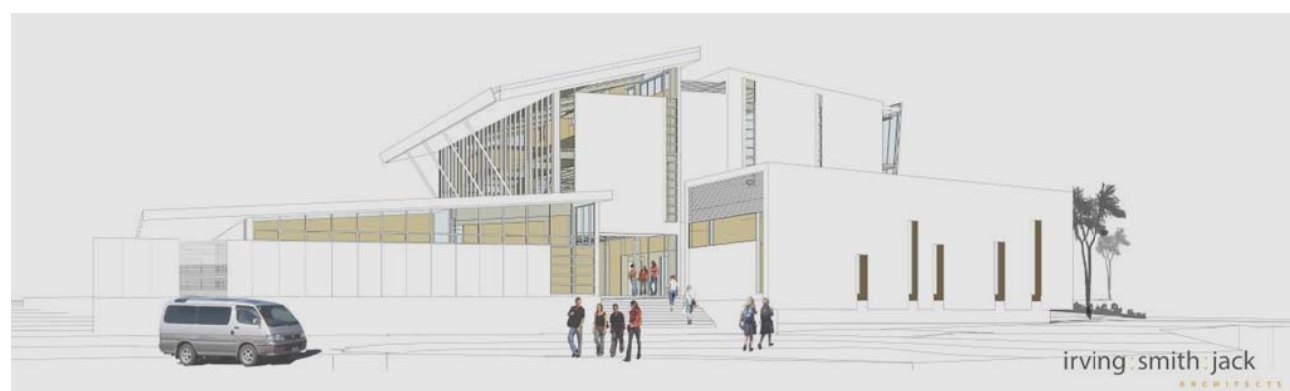

Figure 1. Nelson Marlborough Institute of Technology innovative timber building: Workshop building on the left, Media building on the right, and Arts building at the back (courtesy Irving Smith Jack Architects).

a)

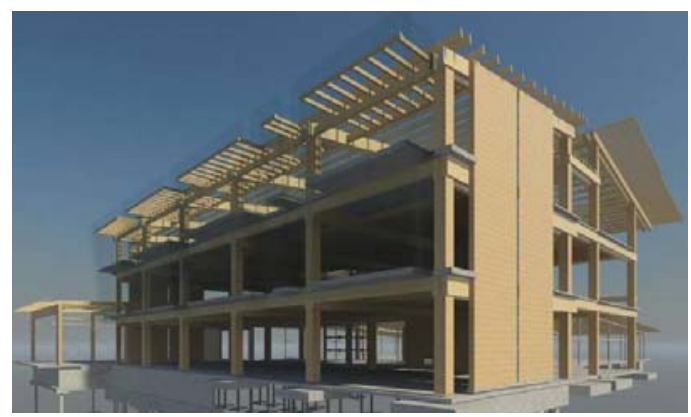

b)

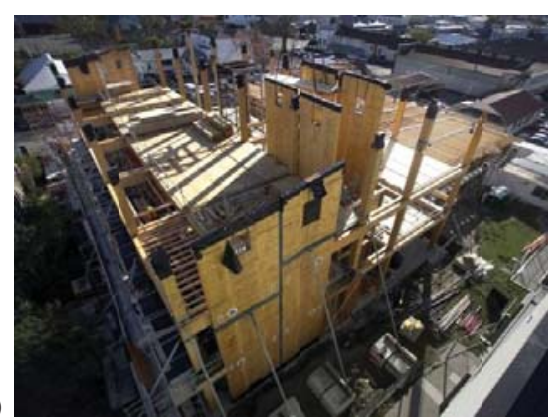

Figure 2. The Arts building: a) structural system with shear walls (courtesy Aurecon), and b) building during construction. 
a)
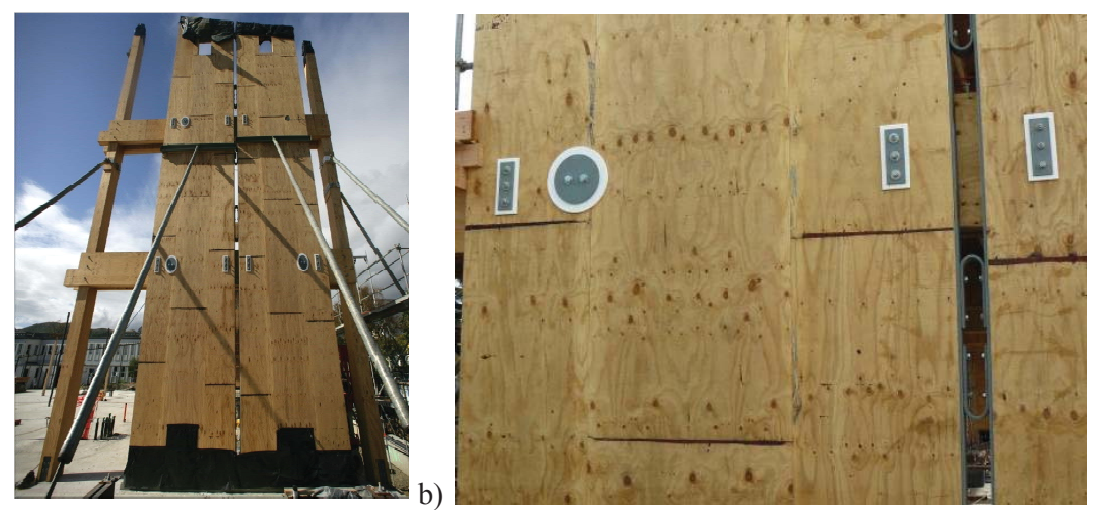

Figure 3. Post-tensioned timber shear wall: a) shear wall during erection, and b) cylindrical shear connectors with Teflon spacer, slotted location bolts and U-shaped yielding steel energy dissipaters.

\subsection{Instrumentation}

The long-term instrumentation was installed mainly in the Arts building with some sensors also in the Media building. The monitoring system can be conceptually broken into four parts: i) a set of tri-axial accelerometers and an anemometer to capture overall dynamic responses of the building due to seismic and strong winds excitation, ii) instrumentation of shear walls to measure dynamic and long-term responses, iii) strain gauges, LVDTs, and temperature and humidity sensors for measuring long-term deformations of structural timber components, iv) a set of uni-axial, vertical accelerometers measuring footfall induced floor vibrations. Systems i)-iii) are described in this section; system iv) is simple as far as the hardware is concerned but required more analyses to decide optimal accelerometer locations and this process is detailed in Section 4.

\subsubsection{Instrumentation for monitoring of overall seismic and winds responses}

Figure 4 shows the NMIT Arts building instrumentation installed for the purpose of measuring the overall building response due to seismic and wind excitations. The system was designed and implemented by GNS Science and is fully integrated with GNS Science's broader GeoNet structural monitoring program comprising several buildings and bridges $^{23}$. The typical sensors are three-axial accelerometers distributed within the building to obtain lateral and torsional modal responses. A reference free field accelerometer for measuring input earthquake ground motions is placed in the best available location (shown as accelerometer 10). Several LVDTs measuring shear wall responses are also a part of this system but are described in the next section. A GPS unit is configured to obtain precise timing to about $1 \mathrm{~ms}$ and a central CUSP-ME-16 data logger by Canterbury Seismic Instruments collects the data at $200 \mathrm{~Hz}$ from the distributed sensors through Ethernet wiring. The stored data are continuously transmitted to GeoNet data centre through a dedicated

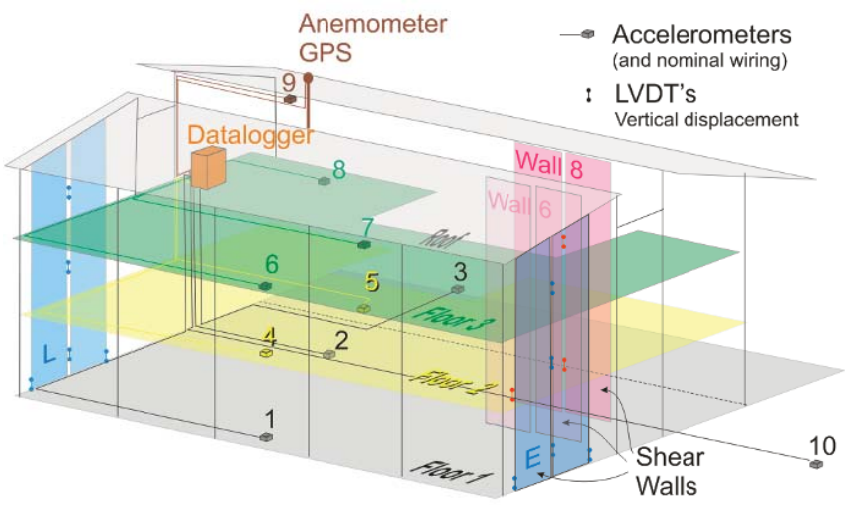

Figure 4. Monitoring system for measuring seismic and wind responses. 
IP connection. The system has backup battery power and beyond nominated acceleration trigger levels the data will be stored locally. In this way, key data are retained even if there is an interruption to the power or data network due to a major wind storm or seismic event. The system was designed to be robust, moderate cost, low maintenance and protected against component obsolescence.

\subsubsection{Instrumentation for monitoring of shear wall responses}

Figure 5 shows the instrumentation of one of the shear walls. For the shear walls, both dynamic and long-term responses are of interest. Dynamic instrumentation consists of RDP Group DCTH LVDTs located at the corners of the wall to measure uplift when the wall rocks, and an additional LVDT measuring deformation across a U-shaped passive energy dissipater. For long-term behavior monitoring, a custom modified CCG series annular ring $450 \mathrm{kN}$ load cells from Applied Measurements Ltd were installed prior to the preliminary post tensioning of the wall and the initial load deformation due to full post tensioning was recorded. Steel weights of $50 \mathrm{~mm}$ diameter were hung from a wire attached at the top of the wall to form a reference for measuring long-term wall shortening. These measurements are taken using LVDTs fixed to the wall foundation. Temperature and humidity are recorded in the major spaces around the shear walls as well as within on exterior shear wall cavity using Vaisala HMP50 sensors. These data will enable a reasonable estimate of the LVL moisture content, known to influence considerably the mechanical properties of timber.

\subsubsection{Instrumentation for monitoring of long-term deformations of structural timber components}

The components of this system are mainly located in the Arts building and their locations are shown in Fig. 6; some additional sensors were also installed in the Media building. Note Fig. 6 also shows long-term shear wall sensors and floor accelerometers, as all these sensors were collected to a National Instruments $533 \mathrm{MHz}$ CRIO-9022 data logger installed by the University of Auckland. Several temperature and humidity sensors were positioned in close proximity to the monitored structural components. The long-term floor sag is monitored with LVDTs using a taut-wire baseline system for the measurement reference ${ }^{24}$. As shown in Fig. 7, a catenary wire is hung over a pulley, in between the 750 $\mathrm{mm}$ deep beams with a $40 \mathrm{~kg}$ mass to maintain constant tension so that temperature compensation is not necessary. Also between the beams, a small trolley reduces dynamic wire flutter for the LVDT contact. A separate system monitors deformation for the $6 \mathrm{~m}$ span floor system.

The Media building has four simple haunched portal frames that are a modest span. As shown in Fig. 8, the instrumentation uses linear "portal" type strain gauges to determine crushing and joint rotation with a vertical LVDT connected to a baseline wire to monitor deformation. Clearance limits mean that a trolley could not be used and the tip of the LVDT is directly fixed to the wire.

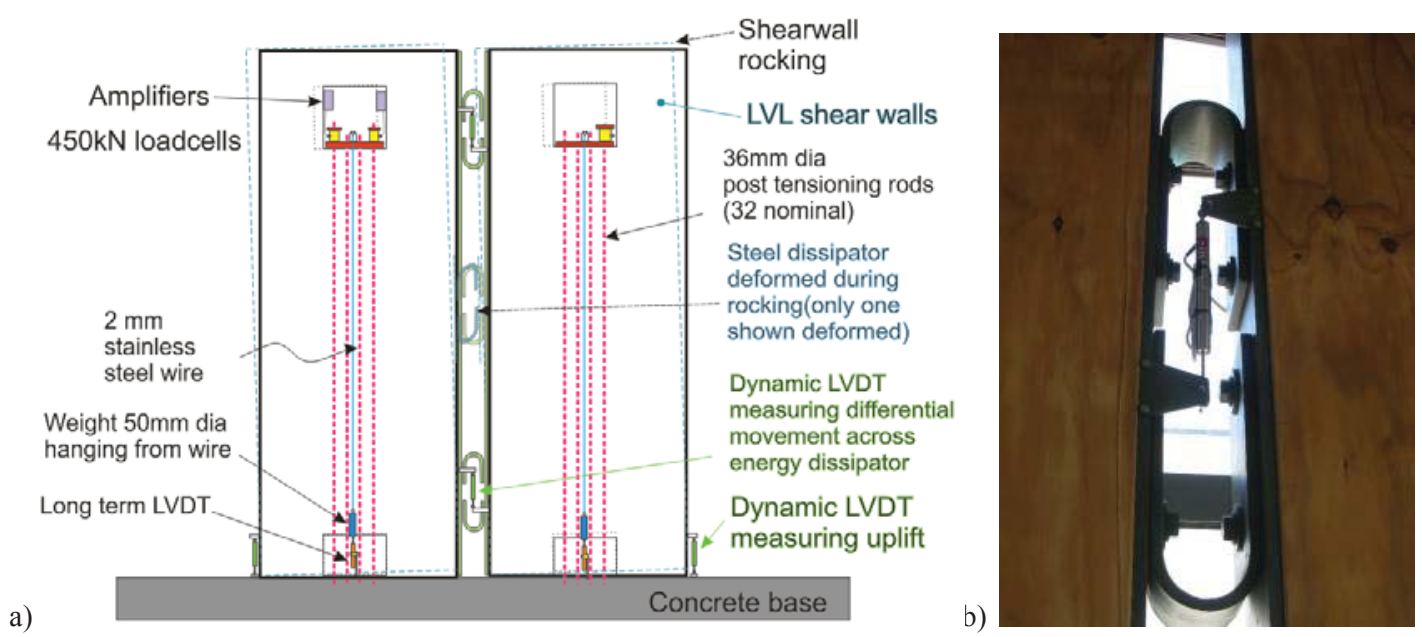

Figure 5. Shear wall instrumentation: a) overall view, and b) LVDT to measure deformation of energy dissipater. 


\section{OPTIMAL SENSOR LOCATION FOR FLOOR VIBRATION MONITORING}

\subsection{Theory}

Deciding on an optimal sensor placement is a common problem encountered in many engineering applications and is a critical issue in the design and implementation of an effective structural health monitoring system ${ }^{25}$. Office floors are often irregular in plan, have openings, uncertain boundary conditions and complex structural systems, resulting in complex dynamics. The loading due to their usage may lead to multimodal response that needs to be captured by a limited number of strategically positioned sensors. A great deal of research has been conducted on optimal sensor placement using a variety of placement techniques and criteria. Meo and Zumpano ${ }^{25}$ compared six different optimal sensor placement techniques and concluded that the effective independence-driving point residue (EfI-DPR) method provides an efficient method for optimal sensor placement to identify the vibration characteristics. This section briefly describes the underlying theory of EfI proposed by Kammer ${ }^{26}$ and Kammer and Tinker ${ }^{27}$.

Consider a problem of acquiring the maximum amount of information about responses of $K$ modes, using $N$ sensors, which can be placed in $M$ possible locations, in such a way that special independence of modes and signal strength are maximized. The $K$ mode shapes at all possible $M$ locations form a matrix:

$$
\boldsymbol{\Phi}_{M \times K}=\left[\begin{array}{llll}
\boldsymbol{\varphi}_{M \times 1}^{(1)} & \boldsymbol{\varphi}_{M \times 1}^{(2)} & \cdots & \boldsymbol{\varphi}_{M \times 1}^{(K)}
\end{array}\right]
$$

where $\boldsymbol{\varphi}_{M \times 1}^{(i)}$ is the $i$-th mode shape measured at $M$ locations. The vector of the measured structural responses, $\mathbf{y}_{M \times 1}$, can be resolved as a combination of $K$ modes through the expression:

$$
\mathbf{y}_{M \times 1}=\boldsymbol{\Phi}_{M \times K} \mathbf{q}_{K \times 1}+\boldsymbol{\omega}_{M \times 1}
$$

where $\mathbf{q}_{K \times 1}$ is the vector of modal coefficients and $\omega_{M \times 1}$ is the vector of stationary, uncorrelated, zero-mean Gaussian

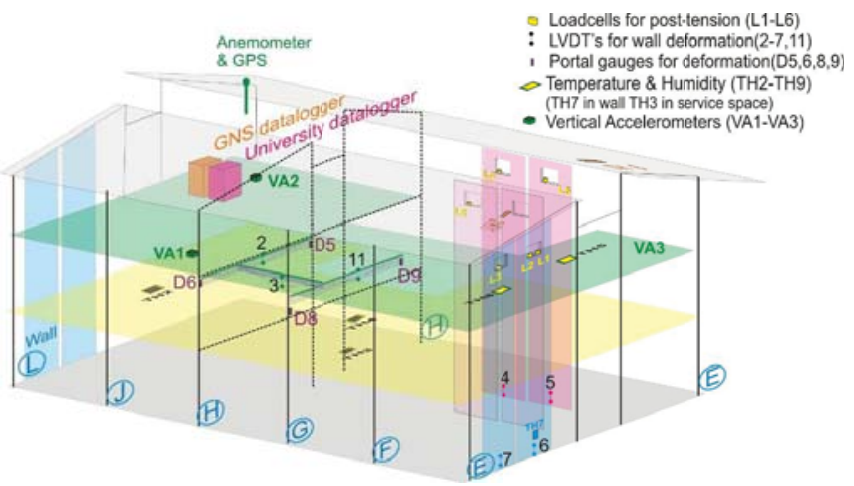

Figure 6. Instrumentation for monitoring of long-term deformations of structural timber components (shear wall sensors and floor accelerometers also shown).

a)

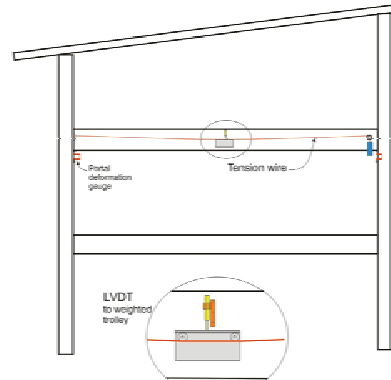

b)

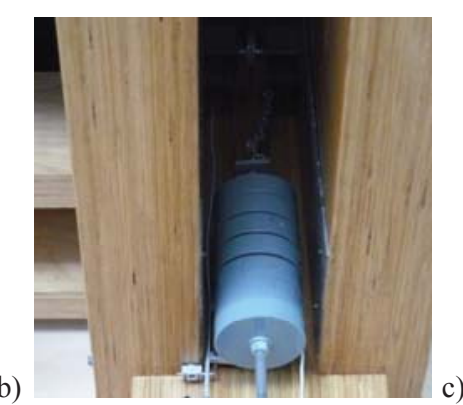

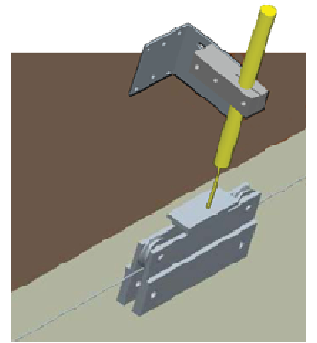

Figure 7. Taut-wire baseline system with an LVDT for long-term beam deformation monitoring: a) overall view, b) wire tensioning weight, and c) LVDT and trolley. 


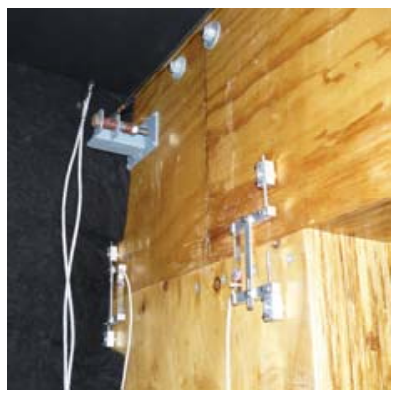

Figure 8. Monitoring knee rotations with "portal" strain gauges.

white noises with a diagonal covariance matrix $\sigma^{2} \mathrm{I}_{M \times M}$. Acquiring information about the modes of interest means estimating their modal coefficients with minimum covariance matrix of the error. The covariance matrix is given by:

$$
\mathbf{P}=\frac{1}{\sigma^{2}}\left(\boldsymbol{\Phi}_{M \times K}^{T} \boldsymbol{\Phi}_{M \times K}\right)^{-1}=\frac{1}{\sigma^{2}} \mathbf{Q}_{K \times K}^{-1}
$$

in which $\mathbf{Q}_{K \times K}$ is the Fisher information matrix. Maximizing a suitable norm of $\mathbf{Q}_{K \times K}$, such as its determinant $\left|\mathbf{Q}_{K \times K}\right|$, leads to the optimal estimation of the modal coefficients. The contribution of each sensor location to the determinant can be calculated taking the diagonal entries of the following matrix:

$$
\mathbf{E}_{M \times M}=\boldsymbol{\Phi}_{M \times K}\left(\boldsymbol{\Phi}_{M \times K}^{T} \boldsymbol{\Phi}_{M \times K}\right)^{-1} \boldsymbol{\Phi}_{M \times K}^{T}
$$

In order to more effectively eliminate locations with low energy content, the diagonal entries of $\mathbf{E}_{M \times M}$ are further weighted by the corresponding driving point residue ${ }^{25}$ :

$$
E_{D i i}=\mathbf{E}_{i i} \sum_{j=1}^{K} \frac{\boldsymbol{\Phi}_{i j}^{2}}{2 \pi f_{j}}
$$

where $f_{j}$ is the $j$-th natural frequency in $\mathrm{Hz}$.

The method starts with calculating the values of $E_{D i i}$ (Eq. (5)) for all possible locations and arranging them according to their magnitudes. The location with the least contribution is then dropped. Because the ranking of contributions of the remaining locations may change after a location is dropped, recalculation of $E_{D i i}$ 's is required. The iterative process stops when the desired number of sensors $N$ is reached. Removing just the location with the least contribution may lead to a suboptimal solution. In the modification we propose here, after the number of candidate locations is suitably reduced by the above traditional elimination approach, at the final optimization steps the search is based on evaluating all possible combinations of $N$ sensors over the remaining locations. Doing so reduces the risk of arriving at a suboptimal solution.

\subsection{Application}

The floor was models using the finite element software ABACUS. The LVL beams were modeled using beam elements and concrete topping using shell elements. Columns of the stories above and below were also included in the model to take into account their influence on floor vibrations. Young's modulus and density were $10.7 \mathrm{GPa}$ and $570 \mathrm{~kg} / \mathrm{m}^{3}$ for timber and $30 \mathrm{GPa}$ and $2,400 \mathrm{~kg} / \mathrm{m}^{3}$ for concrete, respectively.

Modal analysis revealed that there were 22 modes below $12.5 \mathrm{~Hz}$. These were taken into account for optimal sensor placement simulations as they were in the range that could be excited by footfall harmonics. Figure 9 shows several of the lowest frequency modes. It can be seen that due to irregularities and openings in the floor they are localized in either the lower part of floor, where several small classrooms are located, or in both upper corners used for offices and galleries.

The EfI-DPR technique was used to obtain the optimal sensor locations for three sensors. An initial set of 2,189 candidate locations were considered. These were spread fairly evenly over the offices and classrooms but excluded galleries. It was decided that those selected areas, intended for quiet work and thus having more stringent vibration acceptance criteria, received priority. First, locations which gave least contribution to the determinant $\left|\mathrm{Q}_{22 \times 22}\right|$ were 


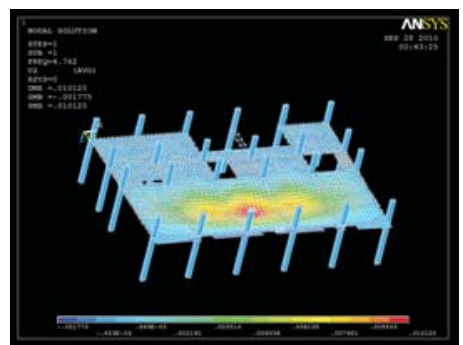

$4.76 \mathrm{~Hz}$

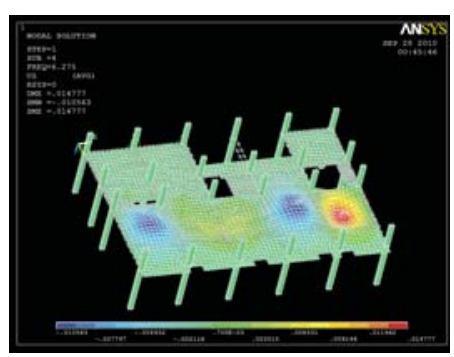

$6.28 \mathrm{~Hz}$

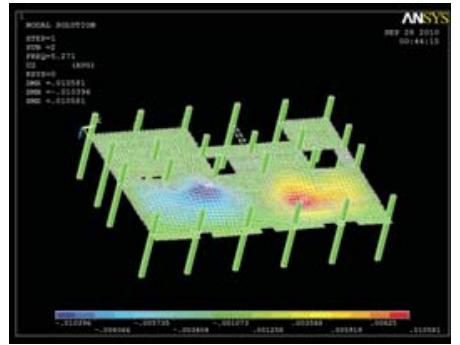

$5.27 \mathrm{~Hz}$

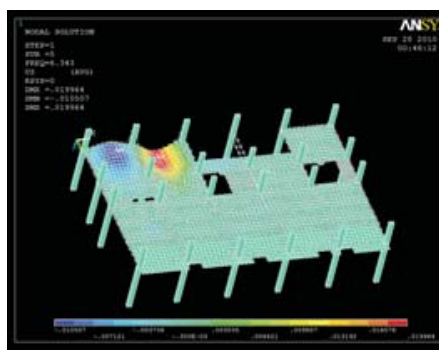

$6.34 \mathrm{~Hz}$

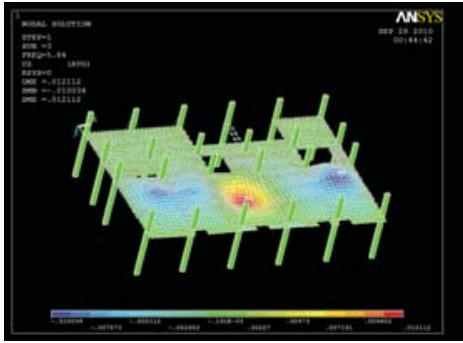

$5.84 \mathrm{~Hz}$

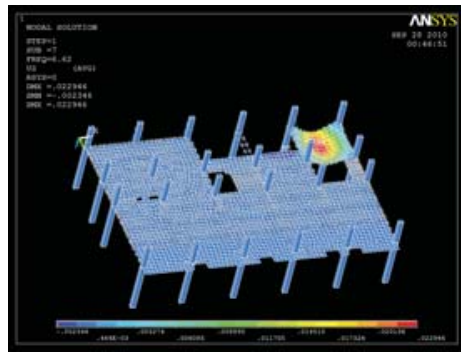

$6.62 \mathrm{~Hz}$

Figure 9. Selected lowest modes of floor vibrations.

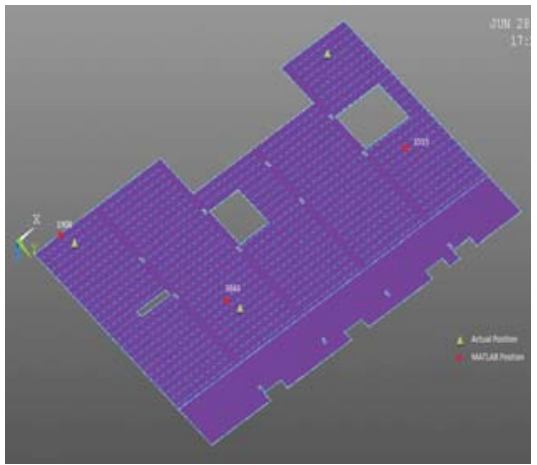

Figure 10. Optimal (red dots) and actual (green triangles) locations of floor accelerometers.

eliminated one by one. When there were 25 candidate locations left, all combinations of three locations out of these 25 remaining were checked. The combination with the highest value of $\left|\mathrm{Q}_{22 \times 22}\right|$ out of the $25 ! /(3 ! \times 22 !)=2,300$ possibilities is shown in Fig. 10 using red dots. Based on the above simulations, three Kistler K-beam 8312B2 capacitive solid state uniaxial accelerometers with $540 \mu \mathrm{g}$ resolution and $1000 \mathrm{mV} / \mathrm{g}$ sensitivity were fixed at the points indicated by green triangles. The actual and optimal locations are nearly the same for two sensors but the third one is located in another room - these shifts were due to practical constraints.

It is noted that switching between the optimal solution search methods increased the computational effort by a factor of less than two. However, the location achieved with the traditional search was only $2,253^{\text {rd }}$ best amongst all the candidates. In fact, the optimal location of three sensors obtained by the proposed approach retained the amount of information comparable to the case of four sensors had the traditional approach to eliminating locations been used to the very end of the search. The actually selected location was ranked $1344^{\text {th }}$ best, still better than the traditionally obtained one, and indicating that shifting the accelerometers did not deteriorate the monitoring system optimality strongly.

7983 - 108 V. 2 (p.10 of 14) / Color: No / Format: A4 / Date: 2011-01-26 01:37:14 AM 


\section{FULL-SCALE DYNAMIC TESTING}

\subsection{Testing program and methodology}

A series of dynamic tests were carried out at six constructions stages in order to observe the changes of stiffness in the building due to structural and non-structural components. Uniaxial Honeywell Q-Flex QA-750 accelerometers were used to measure accelerations for both the ambient vibration testing and the forced vibration testing and two APS Dynamics Model 400 ELECTRO-SEIS long stroke shakers were used to excite the building during the forced vibration testing. During forced vibration testing, the GeoNet accelerometer array (Section 3.2.1) was already operational and these data were also collected. The shakers were capable of a peak $445 \mathrm{~N}$ lateral load in the frequency range from $1 \mathrm{~Hz}$ to $12 \mathrm{~Hz}$. Ambient testing was performed for all six stages and forced testing for the last stage. Unfortunately, only tests for three of the stages yielded reliable results. Table 1 shows the three stages which gave reliable results.

Preliminary finite element models were created to assist with experiment planning, including sensor and shaker locations, and interpretation of results. During forced testing, the shakers were placed on the second floor where several modes of interest could be strongly excited simultaneously with the same shaker setup ${ }^{28}$. However, two shaker setups were used for excitation along the two major axes of the building. Generally, several accelerometer setups were used with reference accelerometer(s) in the same location(s), and mode shapes "glued" together. The accelerometers were placed on the first and second floor but none on the roof. During ambient testing, 60 minute long uninterrupted records were taken, sampled at $100 \mathrm{~Hz}$. Forced testing used either 10 minute long frequency sweeps in the range from $1 \mathrm{~Hz}$ to 8 $\mathrm{Hz}$ and from $8 \mathrm{~Hz}$ to $15 \mathrm{~Hz}$, or broadband random excitation, sampled at $500 \mathrm{~Hz}$.

\subsection{Testing results and discussion}

Experimental data analysis aimed at identification of natural frequencies, damping ratios and mode shapes. Measurements were analyzed using several system identification techniques, including peak picking ${ }^{29}$, enhanced

Table 1. Construction stages and types of dynamic testing performed.

\begin{tabular}{|c|l|l|}
\hline Stage & \multicolumn{1}{|c|}{ Construction progress } & Type of test performed \\
\hline Stage 1 & $\begin{array}{l}\text { Completed frames, partial concrete floor on first story (no diaphragm } \\
\text { action) }\end{array}$ & Ambient \\
\hline Stage 2 & $\begin{array}{l}\text { As above + completed concrete floors (diaphragm action), roofing, } \\
\text { elevator shaft, shears walls post-tensioned, some external cladding }\end{array}$ & Ambient \\
\hline Stage 3 & $\begin{array}{l}\text { As above + completed external cladding, most of internal cladding, } \\
\text { staircase installed }\end{array}$ & Ambient and forced \\
\hline
\end{tabular}

Table 2. Summary of dynamic test results (natural frequencies and damping ratios).

\begin{tabular}{|c|c|c|}
\hline Stage & Frequency & Damping \\
\hline Stage 1 & $\begin{array}{l}\text { Mode } 1: 1.3 \mathrm{~Hz}^{*} \\
\text { Mode } 2: 2.8 \mathrm{~Hz}^{*}\end{array}$ & $\begin{array}{l}\text { Mode 1: - } \\
\text { Mode 2: - }\end{array}$ \\
\hline Stage 2 & $\begin{array}{l}\text { Mode } 1: 2.9 \mathrm{~Hz}^{*} \\
\text { Mode 2: } 3.3 \mathrm{~Hz}^{*}\end{array}$ & $\begin{array}{l}\text { Mode 1: - } \\
\text { Mode 2: - }\end{array}$ \\
\hline Stage 3 & $\begin{array}{l}\text { Mode 1: } 3.45 \mathrm{~Hz}^{*}, 3.53 \mathrm{~Hz}^{\dagger}, 3.27 \mathrm{~Hz}^{\dagger} \\
\text { Mode 2: } 4.1 \mathrm{~Hz}^{*}, 4.07 \mathrm{~Hz}^{\dagger}, 4.14 \mathrm{~Hz}^{\dagger} \\
\text { Mode 3: } 7.42 \mathrm{~Hz}^{\dagger} \\
\text { Mode 4: } 11.86 \mathrm{~Hz}^{\dagger}\end{array}$ & $\begin{array}{l}\text { Mode } 1: 1.6 \%^{\dagger} \\
\text { Mode 2: } 2.4 \%^{\dagger} \\
\text { Mode } 3: 1.8 \%^{\dagger} \\
\text { Mode } 4: 1.7 \%^{\dagger}\end{array}$ \\
\hline
\end{tabular}

*Ambient testing, ${ }^{\dagger}$ Forced testing measured by temporarily deployed sensors, ${ }^{\ddagger}$ Forced testing measured by permanent (GeoNet) sensor array 
Table 3. Summary of dynamic test results (mode shapes).

\begin{tabular}{|c|c|c|c|c|}
\hline \multirow[t]{3}{*}{ Stage } & \multicolumn{4}{|c|}{ Mode } \\
\hline & Mode 1 & Mode 2 & Mode 3 & Mode 4 \\
\hline & $\begin{array}{l}1^{\text {st }} \text { and } 2^{\text {nd }} \text { floor in } \\
\text { phase }\end{array}$ & $\begin{array}{l}1^{\text {st }} \text { and } 2^{\text {nd }} \text { floor in } \\
\text { phase }\end{array}$ & $\begin{array}{l}1^{\text {st }} \text { and } 2^{\text {nd }} \text { floor in } \\
\text { phase }\end{array}$ & $\begin{array}{l}1^{\text {st }} \text { and } 2^{\text {nd }} \text { floor out of } \\
\text { phase }\end{array}$ \\
\hline Stage $1^{*}$ & & & - & - \\
\hline Stage $2^{*}$ & 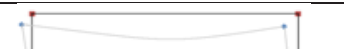 & & - & - \\
\hline Stage $3^{\dagger}$ & & & & \\
\hline & & & 4 & 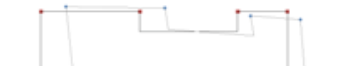 \\
\hline & : : : : & & & \\
\hline
\end{tabular}

*Ambient testing, ${ }^{\dagger}$ Forced testing measured by temporarily deployed sensors

frequency domain decomposition ${ }^{30}$, and data and covariance-driven, output-only and input-output stochastic subspace identification $^{31}$ with stability diagrams. The use of several techniques enhanced the confidence in the modal identification results as only those modes that showed consistency across the various techniques were retained, thus avoiding spurious results often encountered in similar exercises.

Table 2 summarizes the results of dynamic tests providing the natural frequencies and damping ratios identified in the different construction stages and tests. Table 3 shows the corresponding mode shapes for the second floor in planar view (written information about the first floor motion is also provided; no measurements were available for the roof). Note that several tests did not yield all the modes and/or their modal characteristics with high enough confidence, and hence those were omitted from the summary. Overall, all the natural frequencies identified in Stage 3 by the different tests agree very well. Examining the changes in frequencies of Mode 1 and 2 as the construction progressed, it can be clearly seen that the addition of concrete floor topping (and the resulting diaphragm action), addition of the roof and shear wall post-tensioning increased the system stiffness markedly, such that the corresponding natural frequencies increased by $123 \%$ and $18 \%$, respectively. The corresponding mode shapes indicate that the timber frames, previously allowed to move fairly independently, now moved in unison. On the other hand, the changes between Stages 2 and 3 were much less dramatic for Mode 1, increasing the frequency by 24\%, and similar to the previous change for Mode 2, an increase by $17 \%$. It can be thus concluded that cladding had less effect on Mode 1 than the floor completion, roof addition and post-tensioning, but similar on Mode 2. Observing modal shapes of Modes 2, 3 and 4, it can be seen that the floors in fact showed quite appreciable shear-like deformations, indicating that they were quite flexible in their own plane and the degree of diaphragm action was therefore limited. Damping ratios indentified for the complete building (Stage 3) were between $1.6 \%$ and $2.4 \%$, which appears to be within the typical range for such structures at small shaking intensity. The results of these dynamic tests, together with ongoing measurements provided by the GeoNet sensor array, will be used for updating computer structural models and for in depth studies on the amplitude dependence of modal responses and influence of non-structural components, reducing thus the shortage of similar studies.

\section{CONCLUSIONS}

An innovative three-story EXPAN timber building, using self-centering, post-tensioned timber shear walls as the main horizontal load resisting system and lightweight composite timber-concrete floors, has been extensively instrumented for continuous monitoring and also subjected to a number of dynamic tests. The continuous monitoring system intends to 
measure both slowly varying structural responses due to timber creep and fast dynamic responses due to excitations such as seismic and wind and floor vibrations due footfall loading. To that end, the monitoring system comprises about 90 channels of data from strategically positioned sensors measuring structural and ground accelerations, wind speed, static and dynamic displacements, strains, temperature and humidity.

One of the challenges of measuring the multimodal floor dynamic response due to footfall loading was the optimal placement of a limited number of accelerometers (three). This was approached by the EfI-DPR method. The novel approach to solving the optimization problem was the use of a combinatorial search algorithm that increases the chances of obtaining the globally optimal solution, while keeping the computational effort at an acceptable level. It has been demonstrated that the proposed algorithm compared favorably with the traditional approach.

A series of ambient and forced dynamic tests have been conducted on the building at different construction stages and experimental modal identification carried out. These enabled to trace and quantify the effect of the various structural and non-structural components, e.g. floor diaphragms, roof, shear wall post-tensioning and cladding on the building dynamics. It was observed that the floors, roof and post-tensioning increased the fundamental mode frequency by $123 \%$ and the second mode frequency by $18 \%$. Cladding increased the modal frequencies by $24 \%$ and $17 \%$, respectively. The damping ratios for the complete structure at low level elastic response were found to be between $1.6 \%$ and $2.4 \%$.

The continuous monitoring system is now nearly complete and will soon start to collect a wealth of experimental data for in depth studies on long-term and dynamic performance of multistory timber structures.

\section{ACKNOWLEDGEMENTS}

The authors would like to gratefully acknowledge the New Zealand Ministry of Agriculture and Forestry (MAF) for providing funding for instrumentation and dynamic testing. M. Worth was supported by MAF funding to Professor of Timber Design P. Quenneville. V. Kohli was supported by the University of Auckland IIT Summer Internship Program.

\section{REFERENCES}

1. Filiatrault, A., Isoda, H. and Folz, B., "Hysteretic damping of wood framed buildings," Engineering Structures 25 461-471 (2003).

2. Mosalam, K. M. and Mahin, S. A., "Seismic evaluation and retrofit of asymmetric multi-story wood-frame building," Journal of Earthquake Engineering 11 (6), 968-986 (2007).

3. Filiatrault, A., Fischer, D., Folz, B. and Uang, C., "Seismic testing of two-story wood frame house: Influence of wall finish materials," Journal of Structural Engineering, ASCE 128 (10), 1337-1345 (2002).

4. Camelo, V. S., Dynamic characteristics of woodframe buildings. 2003, California Institute of Technology: Pasadena. p. 143.

5. Sutoyo, D., Hysteretic characteristics of wood-frame structures under seismic motions. 2009, California Institute of Technology: Pasadena. p. 151.

6. Filiatrault, A., Christovasilis, I. P., Wanitkorkul, A. and Van De Lindt, J. W., "Experimental seismic response of a full-scale light-frame wood building," Journal of Structural Engineering, ASCE 136 (3), 246-254 (2010).

7. van de Lindt, J. W., Pryor, S. E. and Pei, S., "Shake table testing of a full-scale seven-story steel-wood apartment building," Engineering Structures In Press

8. Ellis, B. R. and Bougard, A. J., "Dynamic testing and stiffness evaluation of a six-storey timber framed building during construction," Engineering Structures 23 (10), 1232-1242 (2001).

9. Filiatrault, A. and Folz, B., "Performance-based seismic design of wood framed buildings," Journal of Structural Engineering 128 (1), 39-47 (2002).

10. Pang, W. and Rosowsky, D. V., "Direct displacement procedure for performance-based seismic design of mid-rise wood-framed structures," Earthquake Spectra 25 (3), 583-605 (2009).

11. Pavic, A. and Reynolds, P., "Vibration serviceability of long-span concrete building floors. Part 1: Review of background information," Shock and Vibration Digest 34 (3), 191-211 (2002).

12. Aalami, B. O., Vibration design of concrete floors for serviceability, ADAPT Corporation, (2008).

7983 - 108 V. 2 (p.13 of 14) / Color: No / Format: A4 / Date: 2011-01-26 01:37:14 AM 
13. Andriacchi, T. P., Ogle, J. A. and Galante, J. O., "Walking speed as a basis for normal and abnormal gait measurements," Journal of Biomechanics 10 (4), 261-268 (1977).

14. Hechler, O., Feldmann, M., Heinemeyer, C. and Galanti, F., Design guide for floor vibrations. 2008, Eurosteel 2008: Graz, Austria. p. 6.

15. Matsumoto, Y., Sato, S., Nishioka, T. and Shiojiri, H., "A study on dynamic design of pedestrian over-bridges," Transactions of the Japan Society of Civil Engineers 4 50-51 (1972).

16. Matsumoto, Y., Nishioka, T., Shiojiri, H. and Matsuzaki, K., "Dynamic design of footbridges," IABSE Proceedings P-17-78 (78), 1-15 (1978).

17. Leonard, D. R., "Human tolerance levels for bridge vibrations," TRRL Report No. 34 (1966).

18. Bachmann, H., Pretlove, A. J. and Rainer, H., "Dynamic forces from rhythmical human body motions," Vibration Problems in Structures: Practical Guidelines (1995).

19. Samarajiva, P. and Choudhuri, D., "Vibration study of a proposed fitness center adjacent to a server room," Proc. Proceedings of the Congress of Forensic Engineering 318-324.

20. Salyards, K. A., Hanagan, L. M. and Kim, C. A., "A unique vibration serviceability case study of a complex structure," Proc. AEI 2006: Building Integration Solutions - Proceedings of the 2006 Architectural Engineering National Conference, 33 (2006).

21. Huston, D. R., Esser, B., Plumpton, J. O. and Zhao, X., "Monitoring of microfloor vibrations in a new research building," Proc. Proceedings of SPIE - The International Society for Optical Engineering, 237-245 (2002).

22. Newcombe, M. P., Pampanin, S. and Buchanan, A. H., "Design, fabrication and assembly of a two-storey posttensioned timber building," Proc. World Conference on Timber Engineering 2010, Trentino, Italy (2010).

23. Uma, S., King, A., Cousins, J. and Gledhill, K., "The GeoNet building instrumentation programme," Bulletin of the New Zealand Society for Earthquake Engineering in press (2011).

24. Stanton, J., Eberhard, M. and Barr, P., "A weighted stretched wire system for monitoring deflections," Engineering Structures 25 347-357 (2003).

25. Meo, M. and Zumpano, G., "On the optimal sensor placement techniques for a bridge structure," Engineering Structures 27 (10), 1488-1497 (2005).

26. Kammer, D. C., "Sensor placement for on-orbit modal identification and correlation of large space structures," Journal of Guidance, Control, and Dynamics 14 (2), 251-259 (1991).

27. Kammer, D. C. and Tinker, M. L., "Optimal placement of triaxial accelerometers for modal vibration tests," Mechanical Systems and Signal Processing 18 (1), 29-41 (2004).

28. Friswell, M. I. and Mottershead, J. E., Finite element model updating in structural dynamics, Kluwer Academic Publishers, Dordrecht (1995).

29. Peeters, B. and de Roeck, G., "Stochastic system identification for operational modal analysis: A review," Journal of Dynamic Systems, Measurement, and Control 123 (4), 659-667 (2001).

30. Gentile, C. and Gallino, N., "Ambient vibration testing and structural evaluation of an historic suspension footbridge," Advances in Engineering Software 39 (4), 356-366 (2008).

31. Peeters, B., System identification and damage detection in civil engineering. 2000, Katholieke Universiteit Leuven: Leuven. p. 238. 